\title{
Study on the official WeChat Business Application in University Library
}

\author{
Jin Dongwang \\ Nanyang Institute of Technology, \\ Nan Yang, He Nan, 473004
}

\begin{abstract}
In development of the new era, the Wechat platform has penetrated people's lives, gradually affect the user's life and learning style and produce major changes in daily life and other aspects. The current official Wechat operation mode of university Library is approaching maturity and gets a good reputation on campus. This paper analyzes the contents of official Wechat operation of the university Library for the better application of official Wechat operation of the university Library and carries on active discussion on its better application in order to provide useful references for the operation and management of university library in the New period.
\end{abstract}

Key Words- University; Library; Official Wechat; Operation; Management

\section{INTRODUCTION}

Wechat is a kind of mobile phone chat software launched by Tencent in 2011. It shows strong development since its appearance and transcend the microblog software which has a wide range of user groups in a short time. The new related data shows that user of this interactive software has reached 300 million until January 2013, which is really a large user base. The whole network users share of Wechat reaches $71.4 \%$, champion in the Internet field and it has fast dissemination of information with a more wide coverage, which interest the library community and set up their own official Wechat. But it is difficult to achieve in-depth promotion for its user and especially it can not meet the requirements on interactive effects and in-depth understanding of user, which is the only way for university library on Wechat operation. It is very important to apply Wechat operation mode in the operation of university library to establish more open channels of two-way interaction and realize grasp of new media in a real sense. ${ }^{1}$

2. Contents analysis of official Wechat operation of university library

Official Wechat of libraries contains news and information, resource sharing, activity reports, interaction outside university and readers activities. In the process of using, most users use the functionality for the information delivery, resource sharing and the user can get the contents they are interested in by means of this method, which further strengthen the user experience and interaction model. At the same time, there are features which has not been fully carried out, such as interaction outside school and online experience for the user etc. It is clearly the focus direction of library operations for a long time in the future. Only this comprehensive development and application can realize the full utilization of the university library official Wechat in a real sense. ${ }^{2-4}$

\subsection{Resource sharing}

Resource sharing is common in various colleges and universities. Function related to 
resource sharing in university has a percent of more than $95 \%$, in particular to specific categories of paper books in university library and also contains a database of information resources. These functions can be obtained effective promotion by means of official Wechat service platform of university library.

\subsection{Activity promotion}

On specific applications, activities promotion is undoubtedly an important part of the official Wechat of university library. It shows according to related statistics that more than $90 \%$ of the library official Wechat platform has been used this function with a specific content of three stage, namely before the event, during the course and after the event.

\subsection{Readers interaction}

Interaction is the biggest feature of official Wechat platform. It is especially true in the application in university library with a strong advantage of two-way communication so as to effectively ensure the strengthening of interaction with the reader. The introduction of this service can more effectively carry out activities such as Q\&A and better reflect service concept of "reader-oriented" .

\subsection{Interaction outside school}

Statistics show that there still exists functions and effective methods such as positive interaction with readers outside school in the current library operations in Chinese Universities. This methods own greater impact while limiting the scope of services provided by the library official Wechat and lacking for interactions with other library in other universities. Because of the lack of communication, the more effective application of official Wechat in other university can not be achieved in the true sense.
2.5 Service extension and fast delivery of library information

With the development of the application environment, it is imperative to extend the service of official Wechat in university library. To be specific, it is demanded to timely and effectively release time arrangements and adjustments, meanwhile, to make statements for the freshman on the use of library resources, especially updating of library resources, internal practical application and other aspects which can form an effective extension of all services to provide users with convenient, thereby improving the user experience and develop long-term users.

\section{Strategy for better application of official Wechat operation in university library}

Expanding the influence is the primary task In order to achieve a better application of the official Wechat. We should systematically expand the influence step by step with the help of publicity channels and only the user knows we can more efficiently promote the service. The next is to show affinity of official Wechat and emphasize its practicality, which is the key factor to attract users. Therefore we should carry out activities with prizes to stimulate the reader in appropriate time so that its reputation and visibility can be improved. We can specifically implement from the following aspects ${ }^{5-6}$ :

\subsection{Improve the readers' awareness}

The reader is undoubtedly the central of library service concept In the development of university education. We can take several service methods and ways to help readers conveniently and quickly obtain the required documents in the process of using library resources. Based on this, we can increase readers' awareness from the following aspects: 


\subsubsection{Promote by the traditional ways of poster}

Many library make advocacy through network channels in current development, such as campus BBS, library website and e-mail push, microblog interaction, etc., so that relevant information about the library is disseminated. We can know according to the results concluded from the small questionnaire survey taken by the author that the number of users obtaining the information about related activity and service from poster set around the library door is larger, reaching more than 50 percent, which shows that traditional channels are still an important force in promotion. Combining with this, the author believes that we should actively use the traditional poster in terms of publicity of official Wechat while designing two-dimensional code of the Wechat as five A4 mini posters, on this basis, to post on the university entrance.

\subsubsection{Use the method of encouraging the reader to spread from mouth to mouth}

Combined with previous promotion experience, it is not enough to only rely on the one-way propaganda of the library on users and it must be explicated that Wechat itself is a two-way interactive communication platform. Therefore, we should play its role in the process of promotion, such as plan a lucky draw spreading by readers from mouth to mouth on the occasion of "reading Day" to earn user reputation for the school and lay a solid foundation for the subsequent user growth.

\subsection{Practicality is the core competence for official Wechat}

The key of operating official Wechat lies in how to retain users and the key to retain customers is practicality. For users of university library, searching their personal borrowed books, book lists of the library and related operations undoubtedly is the most desired items and services. On users composition, the users focusing on Wechat mostly are avid users and mainly search OPAC in the use of Wechat and then is the online consultation and interaction with libraries, etc. For this, we should closely connect OPAC of book lists of library to retain the core competence of user stickiness. We can improve from the following aspects:

\subsubsection{OPAC connect and produce user stickiness}

In the specific implementation, the Wechat public service platform can present the specific operation of users, one of which is a function of information relating to the OPAC, such as collections query, borrowed books and so on. In addition, there is a category in relation to interaction, such as online counseling, Wechat messages and so on. Other related application practice proves that users mainly use the OPAC functionality and also in terms of the use of official Wechat,which is its core competitiveness and we should strengthen the user experience.

\subsubsection{Menu functions strengthen the interface effect}

To achieve improvement of interface effect of library official Wechat, the author recommends that the language presentation style of menu should be uniform and set more official language in the names of service to provide the user with a more proper understanding of services, such as books inquiries. In addition, on the search sorting method, the author suggested a change to the publication date from the order of descending order to the correlation degree to improve the user experience and so on. The final official Wechat menu is in the following figure: 
Binding one-card

Title Unbinding one-card

People in charge $\quad$ Borrowed books Activity notice

Subject term $\quad$ Renewed books New resource

Arbitrary word Hot borrowing About us

Books query

Borrowing information

Borrowing

information

Figure 1 Menu structure of library official Wechat

\subsection{Improve the affinity of library official Wechat}

Library can achieve sending message to all users with this Wechat platform. It is concluded from the previous surveys that mass the most common and most popular is undoubtedly the graphic information, of course, which is also the specific information form of Wechat. In the specific implementation, because the total number of users is always in dynamic growth, the number of users corresponding to each graphic information delivery is different. Therefore we can use the percentage of number of users reading the graphic information in total users proportion to measure the popularity of graphic information. According to the authors' survey, affinity post owns the largest reading quantity. Facing the student users after ninety, the library should change the past official attitude and pay attention to be more closer to user in terms of selection of expression means so that distance between Library and the user can be reduced to improve the user experience and get user acceptance, which is also the direction of development in the future for the University Library.

\section{Conclusion}

In the university libraries operation of new era, we should pay attention to the role of official Wechat in order to achieve the expansion of services and improve the user's usage and bring a new experience for readers by improving the affinity of library official Wechat and usefulness and many other improvements and combine with constant innovative technology and services to make the development of a library more suitable for the needs of users.

\section{References}

[1] Wang Ye, Application analysis of Wechat in university library service[J], Research on Library and Information Work of Shanghai Colleges and Universities,2013,4th issue:37-39.

[2] Zhang Zhen, Ding Guofeng, Application practice of Wechat in university library service taking university libraries in Zhe Jiang for example [J], Library Journal, 2014, $3^{\text {rd }}$ issue.

[3] Huang Qiaojiao, Lei Guangying, Hu Zijuan, Study on application and development of Wechat in university library[J], Science and Technology Innovation Herald, 2013, 27 $7^{\text {th }}$ 
issue:177-178.

[4] Shi Mei, Huo Xiaojuan, Strategy research on official Wechat operation in university library taking library in Nan Jing University for example[J], Journal of Academic Libraries, $2014,5^{\text {th }}$ issue: $79-85$.

[5] Zhu Mengru, Discussion on university library information service based on
Wechat platform[J],China Education Innovation Herald, 2013, 34 ${ }^{\text {th }}$ issue: 271-272.

[6] Wang Zhigang, Application research of Wechat in university information service $[\mathrm{J}]$, Journal of Jilin Teachers College of engineering, 2015, $1^{\text {st }}$ issue: 16-18. 